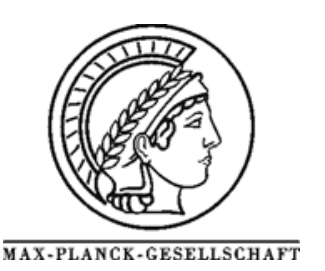

\title{
Direct correlation of the dispersion and structure in vanadium oxide supported on silica SBA-15
}

\author{
C. Hess * \\ Department of Inorganic Chemistry, Fritz-Haber-Institute of the MPG, Faradayweg 4-6, 14195 Berlin, Germany \\ *Corresponding author: e-mail hess@fhi-berlin.mpg.de,
}

Received 14 February 2007; revised 20 February 2007; accepted 24 February 2007; available online 28 March 2007

\begin{abstract}
Raman, UV-Vis and X-ray photoelectron spectroscopy were combined in one experimental setup to directly study the interplay between structure and dispersion of SBA-15 supported vanadium oxide during dehydration. The fully hydrated catalyst is slightly reduced but consists mainly of $\mathrm{V}^{5+}$ species with pseudo-octahedral $\mathrm{V}$ coordination strongly resembling the xerogel $\mathrm{V}_{2} \mathrm{O}_{5} \cdot 1.2 \mathrm{H}_{2} \mathrm{O}$. After dehydration a highly dispersed surface vanadium oxide species with tetrahedrally coordinated vanadium and significantly smaller ensemble size is formed.
\end{abstract}

Keywords: Vanadium oxide; Silica; Water; Dispersion; Structure; UV-vis; Raman; XPS; SBA-15

\section{Introduction}

Water is a common product of selective oxidation reactions. Also, water vapour is often added to the feed to improve the catalyst performance. Despite its importance and extensive research on the influence of water on supported metal oxide catalysts there are still fundamental aspects, which have not been addressed in the literature adequately to their importance, such as changes in catalyst dispersion and their potential correlation with structural changes. ${ }^{1}$ XPS can provide direct information on the dispersion of supported metal oxide catalysts such as vanadium oxide supported on $\mathrm{SiO}_{2}, \mathrm{Al}_{2} \mathrm{O}_{3}$ and $\mathrm{TiO}_{2}$. ${ }^{2}$ However, many of the previous studies were performed on samples exposed to air before being introduced into the XPS chamber without further treatment. Despite the well-known influence of water XPS has been applied only recently to study the effect of dehydration on the vanadium oxide dispersion. $^{3}$

Multiple in situ spectroscopy allows to obtain information from various spectroscopic methods applied to one catalyst sample. A direct correlation of spectroscopic results is possible as any influence of both the particular sample and the reaction cell geometry, which may affect the heating and gas flow conditions, is removed. Recently, three spectroscopic techniques including Raman and UVVis spectroscopy were combined for characterization of supported metal oxide catalysts. ${ }^{4,5}$
In this communcication, the effect of water on both structure and dispersion is studied for a silica SBA-15 supported vanadium oxide model catalyst. In particular, by combining Raman, UV-Vis and X-ray photoelectron spectroscopy (XPS), within one experimental setup, it is shown for the first time that the changes in structure and dispersion upon dehydration are directly correlated. This multiple spectroscopic approach is the first to couple XPS with optical spectroscopic methods. A cross-sectional view of the setup is shown in the inset of Fig.1. Details are given below.

Previous Raman, UV-Vis and EXAFS studies have shown that the presence of water can influence the molecular structure of the surface vanadium oxide species. ${ }^{6-9}$ The structure of the fully hydrated state of silica-supported vanadium oxide species closely resembles $\mathrm{V}_{2} \mathrm{O}_{5} \cdot n \mathrm{H}_{2} \mathrm{O}$ gels with vanadium in pseudo-octahedral coordination forming layers of two-dimensional polyvanadates. Dehydrated vanadium oxide at low $\mathrm{V}$ coverages, i.e. below the coverage at which $\mathrm{V}_{2} \mathrm{O}_{5}$ is formed, has been proposed to be present as isolated tetrahedral $\mathrm{VO}_{4}{ }^{7-9}$ However, a recent IR study provides evidence for the presence of $\mathrm{V}-\mathrm{O}-\mathrm{V}$ implying vanadia dimers or polymers. ${ }^{10}$ Previously, the presence of polymeric species on silica SBA-15 supported vanadia had been suggested on the basis of UV-Vis results. ${ }^{11-14}$ 


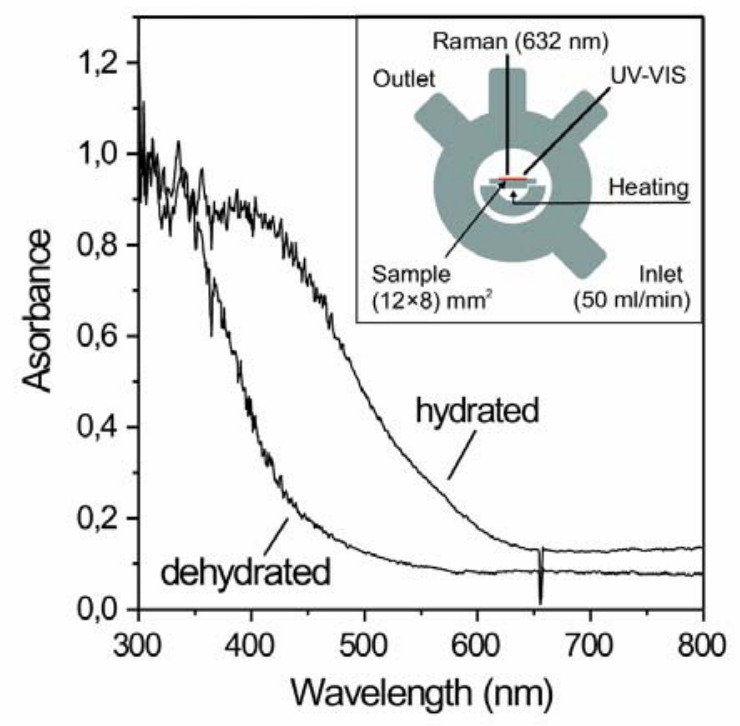

Figure 1: UV-Vis spectra of hydrated and dehydrated V/SBA-15. The inset shows a cross-sectional scheme of the experimental setup illustrating the UV-Vis and Raman capabilities.

For a detailed understanding of catalyst properties, the use of materials with well-defined structure is necessary. Therefore, we have prepared vanadium oxide model catalysts via controlled grafting/anion exchange, which consist of highly dispersed vanadium oxide supported on the inner pores of the well-ordered mesoporous matrix of silica SBA-15. ${ }^{14}$ Only recently, we have demonstrated the excellent catalytic properties of this catalyst system in the propane partial oxidation to acrylic acid as well as methanol partial oxidation to formaldehyde. ${ }^{15}$

\section{Experimental}

Details of the catalyst preparation and characterization are described elsewhere. ${ }^{14}$ Briefly, functionalization of SBA-15 was achieved by adding 3aminopropyltrimethoxysilane to a suspension of SBA-15 in toluene at $65^{\circ} \mathrm{C}$. The contents were filtered, washed and stirred in $0.3 \mathrm{M} \mathrm{HCl}$. For SBA-15 supported vanadium oxide catalysts (V/SBA-15), appropriate amounts of butylammonium decavanadate were added to a suspension of functionalized SBA-15 in water. The resulting yellowish powder was calcined at $550^{\circ} \mathrm{C}$. The SBA-15 reference material was prepared according to the above procedure, however, in the ion-exchange step potassium oxalate monohydrate (Fluka, $>99.5 \%$ ) instead of decavanadate was used. The V/SBA-15 (SBA-15) material had a loading of $3.3 \mathrm{wt} \% \mathrm{~V}$, a specific surface area of $490 \mathrm{~m}^{2} / \mathrm{g}\left(472 \mathrm{~m}^{2} / \mathrm{g}\right)$ and mean pore diameter of $5 \mathrm{~nm}(5.1 \mathrm{~nm})$ as determined from the adsorption branch of the isotherm using $\mathrm{BJH}$ analysis. $\mathrm{V}_{2} \mathrm{O}_{5}$ (Riedel-de Haen, $99.5 \%$ ) was used as purchased.

The measurements were carried out using a LHS/SPECS EA200 MCD system. An evacuation cell of this XPS apparatus was modified to allow for continuous gas flow as well as Raman and UV-Vis fiber probes to be inserted into the cell (see inset of Fig. 1). Powder samples were introduced as is into a stainless steel sample holder with a $0.6 \mathrm{~mm}$ deep rectangular well covering an area of $(12 \times 8) \mathrm{mm}^{2}$. Raman spectra (Kaiser Optical) were measured at $5 \mathrm{~cm}^{-1}$ spectral resolution using $632 \mathrm{~nm}$ excitation at $5 \mathrm{~mW}$ measured at the position of the sample. The spot size at the sample had a diameter of ca. $30 \mu \mathrm{m}$. The spectrometer was calibrated prior to the experiments using a Neon lamp. Sampling times were typically $15 \mathrm{~min}$. UV-Vis spectra were recorded on a HR2000CG (Ocean Optics) using $\mathrm{D}_{2}$ and halogen light sources. The spectrometer was calibrated using $\mathrm{BaSO}_{4}$ as white standard. The sampling time was $1 \mathrm{~min}$. The XPS system was equipped with a $\mathrm{MgK}_{\alpha}$ source $(1253.6 \mathrm{eV}, 168 \mathrm{~W})$. The binding energy scale was calibrated using Au4f $\mathrm{f}_{7 / 2}=84.0 \mathrm{eV}$ and $\mathrm{Cu} 2 \mathrm{p}_{3 / 2}=932.67 \mathrm{eV}$ from foil samples. Spectra were recorded at room temperature. Data acquisition time was $60 \mathrm{~min}$. Charging of the samples was accounted for by setting the peak of the Si2p signal to $103.6 \mathrm{eV} .{ }^{14}$ Further data reduction included satellite deconvolution and subtraction of a Shirley background. Quantitative data analysis was performed on the basis of peak areas by fitting with 30/70 Gauss-Lorentz product functions. Atomic ratios were calculated using empirical cross sections. ${ }^{16}$ The transfer to/from the analysis chamber was performed without air exposure (quasi in-situ).

\section{Results and Discussion}

Figure 1 shows the UV-Vis spectrum of fully hydrated SBA-15 supported vanadium oxide. The spectrum is characterized by a broad $\mathrm{O} \rightarrow \mathrm{V}$ charge transfer band extending up to ca. $650 \mathrm{~nm}$ and a small offset at higher wavelengths $(650-800 \mathrm{~nm})$ with respect to the dehydrated sample. ${ }^{17}$ The presence of absorption above $400 \mathrm{~nm}$ is typical for highly polymerized vanadium oxide species. The offset may indicate the presence of $\mathrm{d}$-d transitions of reduced vanadium oxide. The Raman spectrum of the hydrated V/SBA-15 sample recorded at $632 \mathrm{~nm}$ excitation is depicted in the bottom panel of Fig. 2 together with a spectrum of $\mathrm{V}_{2} \mathrm{O}_{5}$ as reference. The spectrum of V/SBA-15 shows some similarity with that of crystalline $\mathrm{V}_{2} \mathrm{O}_{5}$ but additional bands at 268 and $1021 \mathrm{~cm}^{-1}$ are present. However, the spectrum of V/SBA-15 is in excellent agreement with that of $\mathrm{V}_{2} \mathrm{O}_{5} \cdot 1.2 \mathrm{H}_{2} \mathrm{O}$ recorded by Abello et al. at $647 \mathrm{~nm}$ excitation. ${ }^{18}$ After recording the UV-Vis and Raman spectra the sample was transferred to the XPS analysis chamber. At the bottom of Fig. 3 the V2 $p_{3 / 2}$ emission together with a least-square fit to the data is shown. Comparison with literature data on $\mathrm{V} 2 \mathrm{p}_{3 / 2}$ binding energies (BE) for well-ordered vanadium oxide films allows assigning the bands at $515.9 \mathrm{eV}$ and $517.3 \mathrm{eV}$ to $\mathrm{V}^{3+}$ and $\mathrm{V}^{5+}$, respectively. ${ }^{19}$ Quantitative analysis was performed using three fit functions with constant widths $(\mathrm{FWHM}=2.1 \mathrm{eV})$, which are even lower than those used to describe the well-ordered vanadium oxide films ${ }^{19}$ confirming the homogeneity of our 


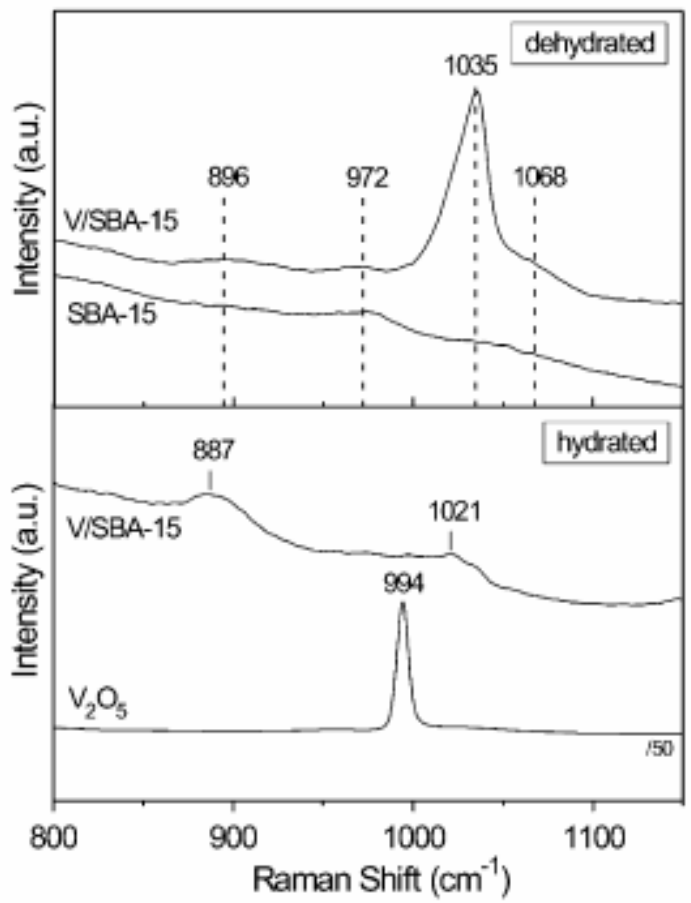

Figure 2: Top panel: Raman spectra of dehydrated V/SBA-15 (top) and bare SBA-15 (bottom). Bottom panel: Raman spectra of hydrated V/SBA-15 (top) and $\mathrm{V}_{2} \mathrm{O}_{5}$ (bottom). The spectra are offset for clarity.

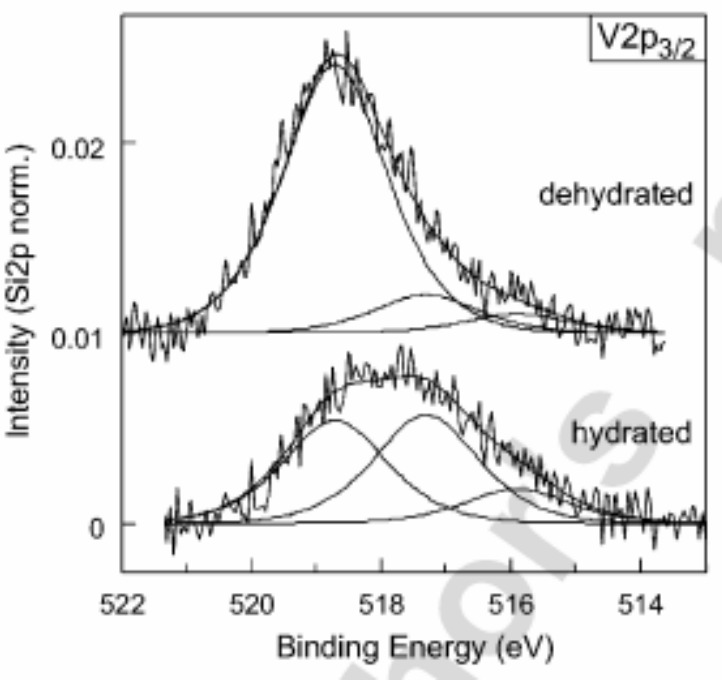

Figure 3: XPS V2p $\mathrm{p}_{3 / 2}$ spectra of hydrated (bottom) and dehydrated (top) V/SBA-15 together with the results of the fit analysis. The spectra are offset for clarity. For details see text.

powder model system. EPR experiments on the fully hydrated V/SBA-15 sample gave a $\mathrm{V}^{4+}$ signal corresponding to only $0.3 \%$ of the total amount of vanadium. Therefore, XPS confirms the UV-Vis results and identifies the reduced vanadium oxide as $\mathrm{V}^{3+}$ species.

After XPS analysis the sample was transferred back into the reaction cell, heated to $300^{\circ} \mathrm{C}$ and treated at $300^{\circ} \mathrm{C}$ for $30 \mathrm{~min}$ in $20 \% \mathrm{O}_{2} /$ He flow. Upon dehydration, dramatic
Table 1: Results of the XPS V2 $\mathrm{p}_{3 / 2}$ analysis of SBA-15 supported vanadium oxide.

\begin{tabular}{lllll}
\hline & $\begin{array}{l}\text { Position } \\
(\mathrm{eV})\end{array}$ & $\begin{array}{l}\text { Width } \\
(\mathrm{eV})\end{array}$ & $\begin{array}{l}\% \\
(t=60 \mathrm{~min})\end{array}$ & $\begin{array}{l}\% \\
(t=0 \mathrm{~min})\end{array}$ \\
\hline $3.3 \mathrm{wt} \%$ V/SBA-15 & 518.7 & 2.1 & 41.6 & 44.0 \\
(hydrated) & 517.3 & 2.1 & 44.4 & 53.2 \\
& 515.9 & 2.1 & 14.0 & 2.8 \\
$3.3 \mathrm{wt} \%$ V/SBA-15 & 518.7 & 2.1 & 82.3 & 83.4 \\
after $\mathrm{O}_{2}$ treatment & 517.3 & 2.1 & 11.9 & 16.4 \\
(dehydrated) & 515.9 & 2.1 & 5.8 & 0.2 \\
\hline
\end{tabular}

changes were observed in all spectra. The Raman and UVVis spectra are depicted in Fig.1 and in the top panel of Fig. 2 , respectively. The UV-Vis spectrum shows absorption due to $\mathrm{O} \rightarrow \mathrm{V}$ charge transfer bands which extends up to ca. $450 \mathrm{~nm}$. Such an absorption behavior is typical for reference compounds with tetrahedrally coordinated vanadium such as $\mathrm{Mg}_{2} \mathrm{~V}_{2} \mathrm{O}_{7}$ or $\mathrm{NH}_{4} \mathrm{VO}_{3}$. In contrast, orthovanadate reference compounds such as $\mathrm{Mg}_{3} \mathrm{~V}_{2} \mathrm{O}_{8}$ exhibit an absorption band which extends only up to ca. $400 \mathrm{~nm}$. The Raman spectrum of V/SBA-15 shows strong features around 1035 and $1068 \mathrm{~cm}^{-1}$ along with smaller features around 896 and $972 \mathrm{~cm}^{-1}$. The Raman bands at 896, 1035 and $1068 \mathrm{~cm}^{-}$ ${ }^{1}$ are observed only after deposition of vanadium oxide. The additional feature at $972 \mathrm{~cm}^{-1}$ is characteristic of the Si-OH stretching mode of surface hydroxyls. ${ }^{20}$ Upon grafting of vanadium oxide, its intensity decreases as a result of the reaction $\mathrm{Si}-\mathrm{OH}$ with the vanadium oxide precursor. The Raman band around $1035 \mathrm{~cm}^{-1}$ has an asymmetric band shape with a shoulder at $1068 \mathrm{~cm}^{-1}{ }^{21}$ It is assigned to the $\mathrm{V}=\mathrm{O}$ stretch vibration of tetrahedrally coordinated $\mathrm{V}$ ions. The features at $896 \mathrm{~cm}^{-1}$ can either be due to vibrations of the surface vanadium oxide species or changes related to the silica surface upon grafting of vanadium oxide. In summary, the UV-Vis and Raman data suggest that after dehydration both isolated and small aggregates of polymerized $\mathrm{VO}_{4}$ units with tetrahedrally coordinated $\mathrm{V}$ ions are present. $^{10}$

After the Raman and UV-Vis analysis the sample was cooled to room temperature and transferred to the XPS chamber. Figure 3 shows the V2 $\mathrm{p}_{3 / 2}$ emission of dehydrated SBA-15 supported vanadium oxide (top spectrum) together with a least-square fit to the data. After dehydration a dramatic shift in intensity to higher BE is observed. Quantitative analysis yields an intensity increase of the band around $518.7 \mathrm{eV}$ from $42 \%$ to $82 \%$, whereas the band centered at $517.3 \mathrm{eV}$ shows an intensity decrease from $44 \%$ to $12 \%$. The presence of $6 \% \mathrm{~V}^{3+}$ in dehydrated V/SBA-15 is a result of the sample reduction by UHV/X-rays. However, timedependent XPS analysis shows that for the dehydrated sample at $\mathrm{t}=0$ no significant amount of $\mathrm{V}^{3+}$ is present (see Table 1). ${ }^{3}$ It is evident that the band around $518.7 \mathrm{eV}$ can not solely be described by a change in oxidation state (see above). However, final state effects are known to result in size-dependent BE shifts for small conducting particles on insulating substrates. ${ }^{22}$ This situation applies to small vanadium oxide particles with $\mathrm{V}$ ions in oxidation state $3+$ and vanadyl groups at the surface, which are known to be formed under reduced-pressure conditions. ${ }^{23}$ In accordance 
with these results the $\mathrm{V}$ ions in our SBA-15 supported vanadium oxide particles are suggested to be partly reduced from $5+$ to $3+$ upon transfer to the analysis chamber, which only renders possible the analysis of their size changes. In summary, our XPS results directly show that dehydration of the catalyst is accompanied by a strong decrease in cluster size, i.e., an increase in the dispersion of the catalyst. Our results strongly suggest that upon dehydration most of the surface vanadium oxide is subject to a significant decrease in cluster size. The fact that the band at $518.7 \mathrm{eV}$ is also present for the hydrated sample indicates that water from ambient significantly reduces the dispersion of part but not all of the surface vanadium oxide species.

In conclusion, using a new experimental setup the correlation between changes in structure and dispersion has been studied directly for the first time as demonstrated for the dehydration of a well-defined SBA-15 supported vanadium oxide catalyst. The dehydrated state of our model catalyst serves as a perfect starting point to study the catalyst' changes associated with the transition into its active

\section{References and Notes}

[1] Gryzbowska-Swierkosz, B., Top. Catal. 11/12, 23 (2000).

[2] Inumaru, K., Misono, M., Okuhara, T., Appl. Catal. A 149, 133 (1997); Bond, G.C., Zurita, J.P., Flamerz, S., Appl. Catal. 27, 353 (1986).

[3] Hess, C., Schlögl, R., Chem. Phys. Lett. 432, 139 (2006).

[4] Brückner, A., Chem. Comm. 1761 (2005).

[5] Beale, A.M., van der Eerden, A.M.J., Kervinen, K., Newton, M.A., Weckhuysen, B.M., Chem. Comm. 3015 (2005).

[6] Schraml-Marth, M., Wokaun, A., Pohl, M., Krauss, H.L., J. Chem. Soc. Faraday Trans. 87, 2635 (1991).

[7] Xie, S., Iglesia, E., Bell, A.T., Langmuir 16, 7162 (2000).

[8] Gao, X., Bare, S.R., Weckhuysen, B.M., Wachs, I.E., J. Phys. Chem. B 102, 10842 (1998); Jehng, J.-M., Deo, G., Weckhuysen, B.M., Wachs, I.E., J. Mol. Catal. A 110, 41 (1996).

[9] Keller, D.E., Visser, T., Soulimani, F., Koningsberger, D.C., Weckhuysen, B.M. Vibr. Spectrosc. 43, 140 (2007).

[10] Venvov, T.V., Hess, C., Jentoft, F.C., Langmuir 23, 1768 (2007).

[11] Fornes, V., Lopez, C., Lopez, H.H., Martinez, A. Appl. Catal. A 249, 345 (2003).

[12] Liu, Y.-M., Cao, Y., Li, N., Feng, W.-L., Dai, W.-L., Yan, S.R., He, H.-Y., Fan, K.-N. J. Catal. 224, 417 (2005).

[13] Kustrowski, P., Segura, Y., Chmielarz, L., Surman, J., Dziembaj, R., Cool, P., Vansant, E.F. Catal. Today 114, 307 (2006). state with the fully hydrated catalyst resembling the upper limit in the water containing catalyst environment during partial oxidation reactions.

\section{Acknowledgement}

The author wishes to thank Oksana Storcheva for performing the EPR experiments and Robert Schlögl for continuous support. This research was supported by SFB 546 of the Deutsche Forschungsgemeinschaft (DFG). C.H. thanks the DFG for an Emmy Noether fellowship.

[14] Hess, C., Hoefelmeyer, J.D., Tilley, T.D., J. Phys. Chem. B 108, 9703 (2004); Hess, C., Wild, U., Schlögl, R., Microp. Mesop. Mater. 95, 339 (2006) and references therein.

[15] Hess, C., Looi, M.H., Abd Hamid, S.B., Schlögl, R., Chem. Comm. 451 (2006); Hess, C., Drake, I.J., Hoefelmeyer, J.D., Tilley, T.D., Bell, A.T., Catal. Lett. 105, 1 (2005); Hess, C. Surf. Sci. 600, 3695 (2006).

[16] Briggs, D., Seah, M.P. Practical Surface Analysis, Wiley: Chichester, 1990.

[17] The sharp feature at $656 \mathrm{~nm}$ is an artifact of the UV-Vis spectrometer.

[18] Abello, L., Husson, E., Repelin, Y., Lucazeau, G., J. Solid State Chem. 56, 379 (1985).

[19] Dupuis, A.-C., Abu Haija, M., Richter, B., Kuhlenbeck, H., Freund, H.-J., Surf. Sci. 539, 99 (2003).

[20] Stolen, R.H., Walrafen, G.E., J. Chem. Phys. 64, 2623 (1976).

[21] The presence of a vanadia-related band with significant intensity at $1068 \mathrm{~cm}^{-1}$ was confirmed by preliminary UV-Raman experiments in collaboration with Peter Stair.

[22] Wertheim, G.K., Z. Physik. B 66, 53 (1987).

[23] Guimond, S., Abu Haija, M., Kaya, S., Lu, J., Weissenrieder, J., Shaikhutdinov, S., Kuhlenbeck, H., Freund, H.-J., Döbler, J., Sauer, J., Top. Catal. 38, 117 (2006). 